\title{
Boundary Layer Transition and Trip Effectiveness on an Apollo Capsule in the JAXA High Enthalpy Shock Tunnel (HIEST) Facility
}

\author{
Lindsay C. Kirk*, Randolph P. Lillard ${ }^{\dagger}$ \\ NASA Johnson Space Center, Houston, TX 77058 \\ Joseph Olejniczak ${ }^{\ddagger}$ \\ NASA Ames Research Center, Moffett Field, CA 94035 \\ Hideyuki Tanno ${ }^{\S}$ \\ JAXA Kakuda Space Center, Kakuda, Miyagi, 9811525 Japan
}

\begin{abstract}
Computational assessments were performed to size boundary layer trips for a scaled Apollo capsule model in the High Enthalpy Shock Tunnel (HIEST) facility at the JAXA Kakuda Space Center in Japan. For stagnation conditions between $2 \mathrm{MJ} / \mathrm{kg}$ and $20 \mathrm{MJ} / \mathrm{kg}$ and between $10 \mathrm{MPa}$ and $60 \mathrm{MPa}$, the appropriate trips were determined to be between $0.2 \mathrm{~mm}$ and $1.3 \mathrm{~mm}$ high, which provided $k / \delta$ values on the heatshield from 0.15 to 2.25 . The tripped configuration consisted of an insert with a series of diamond shaped trips along the heatshield downstream of the stagnation point.

Surface heat flux measurements were obtained on a capsule with a $250 \mathrm{~mm}$ diameter, $6.4 \%$ scale model, and pressure measurements were taken at axial stations along the nozzle walls. At low enthalpy conditions, the computational predictions agree favorably to the test data along the heatshield centerline. However, agreement becomes less favorable as the enthalpy increases conditions. The measured surface heat flux on the heatshield from the HIEST facility was under-predicted by the computations in these cases. Both smooth and tripped configurations were tested for comparison, and a post-test computational analysis showed that $k / \delta$ values based on the as-measured stagnation conditions ranged between 0.5 and 1.2. Tripped configurations for both $0.6 \mathrm{~mm}$ and $0.8 \mathrm{~mm}$ trip heights were able to effectively trip the flow to fully turbulent for a range of freestream conditions.
\end{abstract}

\section{Introduction}

A 6.4\% scale model of the Apollo entry capsule was tested in the High Enthalpy Shock Tunnel (HIEST) facility at the Japan Aerospace Exploration Agency's Kakuda Space Center (JAXA-KSC). A range of stagnation enthalpy and stagnation pressure conditions were tested to gather data to help improve computational simulation accuracy at high enthalpy conditions, to assess boundary layer trip effectiveness at high enthalpy conditions, and to further investigate anomalous surface heat flux data previously obtained in the HIEST facility and other high enthalpy facilities such as the T5 facility at the California Institute of Technology ${ }^{2}$. The details of the HIEST test campaign with the Apollo capsule examined in this work have been reported by Tanno et. al. in a separate publication ${ }^{3}$.

For reentry vehicles returning through Earth's atmosphere on high energy trajectories, such as those from the moon or Mars, chemistry effects play a substantial role in the aerodynamic heating to the vehicle surface**REFERENCE**. Computational tools are able to predict the heating environments for these high enthalpy conditions where chemistry is important, but the accuracy of and the uncertainties inherent in these predictions are generally less understood than those of lower enthalpy conditions because there is less quality validation data available at the higher energy conditions. Ground test facilities are limited in the conditions that can be reached at higher pressure and enthalpy conditions, so much of the validation data for flight-like high enthalpy conditions comes from flight test data. Flight test data is able to measure the flight environment, but understanding the data and quantitatively assessing the uncertainties in computational predictions is hindered by larger measurement uncertainties such as those due to trajectory uncertainties, instrumentation installation uncertainties, and flight data reconstruction uncertainties. **ADD MORE HERE**

\footnotetext{
*Aerospace Engineer, AIAA Member

${ }^{\dagger}$ Chief, Thermal Design Branch

${ }^{\ddagger}$ Manager, Orion MPCV Aerosciences

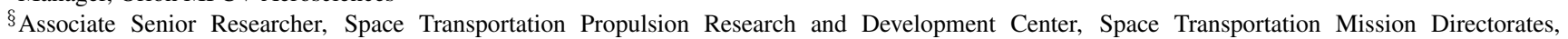
tanno.hideyuki@jaxa.jp, AIAA member
} 
The analysis presented here will focus on the computational analysis of the data obtained at the HIEST facility. A pretest analysis supported the design of the model and the trip insert, which was comprised of a series of "pizza box" trip elements and located downstream of the stagnation point. The post-test analysis consists of an evaluation of the predictive capability of the capsule surface quantities for a smooth configuration at high enthalpy conditions and an assessment of the effectiveness of the trips that were designed in the pretest analysis. An additional assessment of the accuracy of the predicted pressures on the nozzle wall is included to help understand the comparisons on the capsule surface.

\section{A. HIEST Facility Overview}

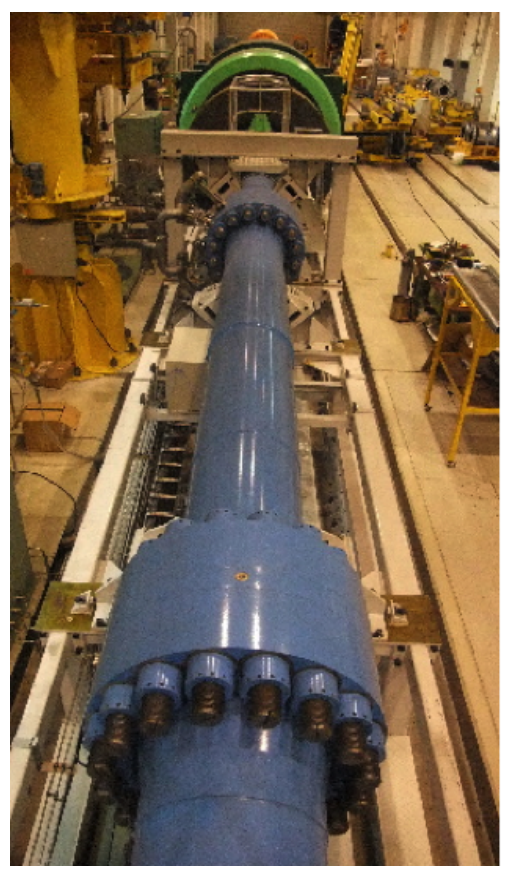

Figure 1. HIEST Shock Tube Facility
The HIEST high enthalpy facility at the JAXA-KSC facility is a free piston shock tunnel designed to simulate the real gas effects at high temperatures such as those seen by spacecraft reentering the atmosphere ${ }^{1}$. The facility measures just over 90 meters in length and has both a conical nozzle and a contoured nozzle to reach a range of velocities from $3 \mathrm{~km} / \mathrm{s}$ to $7 \mathrm{~km} / \mathrm{s}$. The HIEST can operate at conditions up to a maximum stagnation enthalpy of $25 \mathrm{MJ} / \mathrm{kg}$ and a maximum stagnation pressure of $150 \mathrm{MPa}$, and test times are at least 2 msec. Figure 1 shows the shock tube and inertia mass of the HIEST free-piston shock tunnel.

\section{Numerical Simulation Methodology}

The computational analysis for this work was performed using the DataParallel Line Relaxation (DPLR) ${ }^{4}$ software v4.02.2 developed at the NASA Ames Research Center. DPLR is a finite-volume Navier-Stokes solver that is capable of modeling thermal and chemical non-equilibrium, both of which are important for predicting reentry flight conditions and high enthalpy flows in ground test facilities. All simulations for this analysis were completed using a five species air chemistry model, and diffusion and transport properties were modeled using the Self-Consistent Effective Binary Diffusion (SCEBD) model and Gupta-Yos transport models, respectively. To reduce complexity, the nozzle and capsule simulations were run independently. Both simulations, however, used the same physical models in the simulation for consistency.

\section{A. Nozzle Calculations}

Freestream conditions for the Apollo capsule simulations were extracted from axisymmetric nozzle simulations where the flow was expanded through the nozzle throat from a subsonic artificial wall extension. The flow for each run was assumed to be in chemical equilibrium at the stagnation pressure and enthalpy provided by the test facility. Equilibrium conditions for a five-species air chemistry model were computed using Chemical Equilibrium with Applications (CEA) ${ }^{5}$.

The grid resolution for the nozzle simulations was 178 cells in the axial direction and 600 cells in the radial direction for a total of approximately 105,000 cells. Figure 2 shows a sample nozzle simulation for a stagnation pressure for $45 \mathrm{MPa}$ and a stagnation enthalpy of $20 \mathrm{MJ} / \mathrm{kg}$.

A study of the nozzle wall catalycity was performed using both catalytic and non-catalytic boundary conditions. The results showed that, for a case with a stagnation enthalpy of $20 \mathrm{MJ} / \mathrm{kg}$ and a stagnation pressure of $20 \mathrm{MPa}$, the wall catalycity had little effect on the core flow or the wall boundary layer parameters, specifically the height and momentum thickness Reynolds number, $R_{\theta}$. As a result, all subsequent nozzle simulations were run with a non-catalytic boundary condition.

A similar study of the effects of the chosen turbulence model on the core flow was completed using a laminar flow assumption as well as a turbulent flow assumption using the Spalart-Allmaras (SA) and Shear Stress Transport (SST) turbulence models. Figure 3 shows the effect of each of these modeling assumptions on the Mach number at the assumed model location. Little difference in the Mach number was observed between the two turbulent solutions, so all subsequent simulations were run with the SST turbulence model. 




Figure 2. Nozzle simulation for $P_{0}=45 \mathrm{MPa}$ and $\mathrm{H}_{0}=20 \mathrm{MJ} / \mathrm{kg}$ with Mach number on top and translational temperature on bottom.

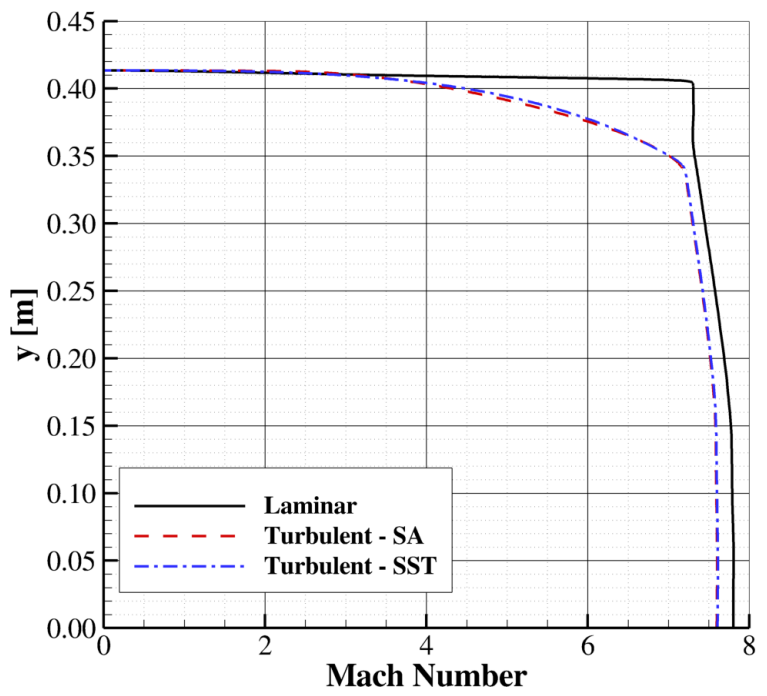

Figure 3. Nozzle Turbulence Model Effect on Core Mach Number 


\section{B. Capsule Calculations}

The test article used in the test series was an axisymmetric idealized model of the Apollo capsule with heat flux instrumentation along the heatshield centerline and off-centerline on the leeside of the heatshield. All simulations were run with a smooth, heatshield only, half-body grid to reduce the computational cost. The heatshield only approximation was made due to the lack of instrumentation on the model backshell, and all conditions were tested at $28^{\circ}$ angle of attack with no side slip so a symmetrical simulation was also an appropriate approximation. This resulted in a grid size of approximately $2.5 \mathrm{M}$ cells, with 160 cells in the off-body direction.

The nozzle simulations showed that the flow at the location of the test article was approximately uniform across the nozzle cross section, and this was seen in Figure 3. As a result, the freestream conditions for the capsule simulations were extracted at the nozzle centerline. Figure 4 shows the assumed model location within the nozzle.



Figure 4. Assumed test article location within the nozzle

Once the freestream conditions for each run were extracted from the nozzle simulations, the capsule simulations were completed assuming both laminar and turbulent flow assuming an isothermal wall boundary condition of $300 \mathrm{~K}$. Turbulent simulations were run with the Baldwin-Lomax and SST turbulence models. The wall boundary condition was initially assumed to be non-catalytic, but it was also expected that catalytic effects would become more important as the enthalpy increased. For a higher enthalpy run, $H_{0}=20 \mathrm{MJ} / \mathrm{kg}$, at a high stagnation pressure of $40 \mathrm{MPa}$, an additional simulation with a fully catalytic wall boundary condition was completed for comparison. Figure 5 shows this comparison and the nearly negligible difference between the wall heat transfer resulting from the non-catalytic boundary condition and that of the fully catalytic boundary condition. The largest differences, which are still minimal, are seen near the windside shoulder. When comparing the computational results to the data measured at these conditions, both wall catalycity assumptions significantly under-predict the data. From this result, wall catalycity appears to provide a small amount of uncertainty in predicting the surface heat flux measured in the tunnel. However, some phenomenon appears to be missing from the simulations that is contributing to the large discrepancy between the computational predictions and the measured data. This result is consistent with some testing shown by Marineau, et. al. in the T5 high enthalpy facility at CalTech ${ }^{2}$. Additional investigation at the HIEST facility, particularly with respect to sources of radiation that could be causing this increased heating, is currently under way and results will be published at a later date.

A sample of the capsule simulations for a high pressure $\left(P_{0}=50 \mathrm{MPa}\right)$ and low enthalpy $\left(H_{0}=10 \mathrm{MJ} / \mathrm{kg}\right)$ condition can be seen in Figure 6. The laminar and two turbulent solutions can be seen in separate surface heat flux maps in addition to a plot comparing the computational predictions along the centerline to the smooth and tripped data measured in the tunnel. 


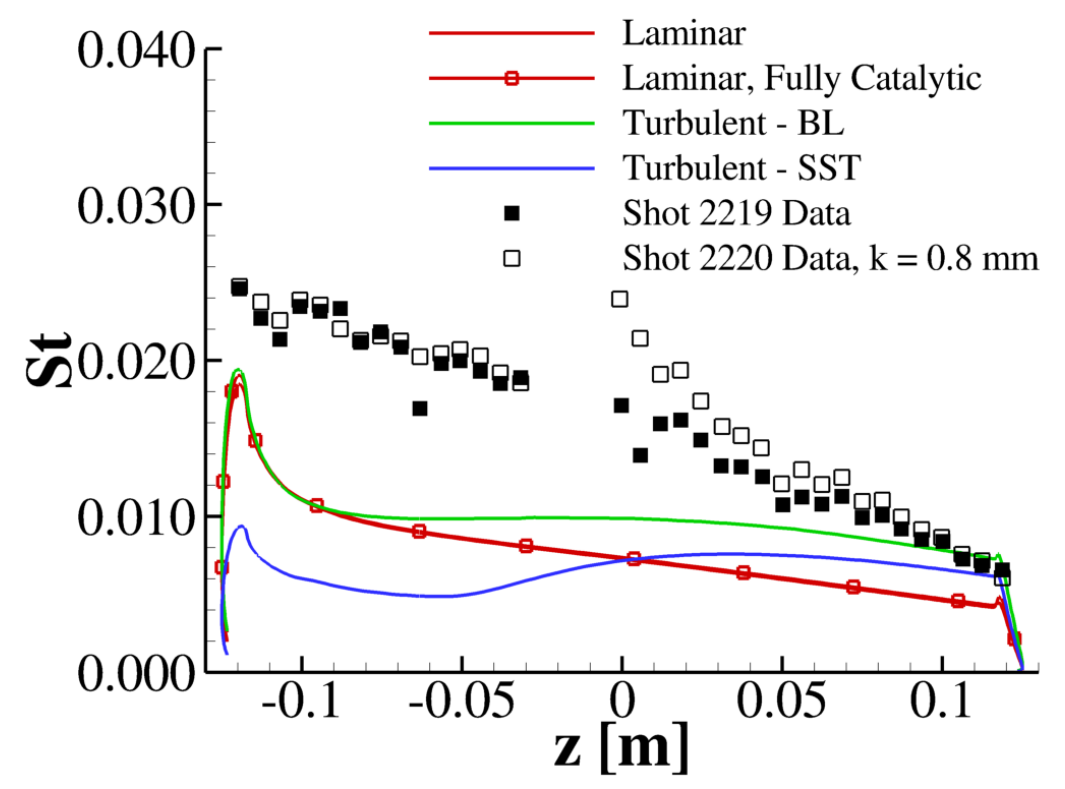

Figure 5. Shot 2220 with Non-catalytic and Fully Catalytic Wall Boundary Conditions, $H_{0}=20.75 \mathrm{MJ} / \mathrm{kg}, P_{0}=41.54 \mathrm{MPa}$
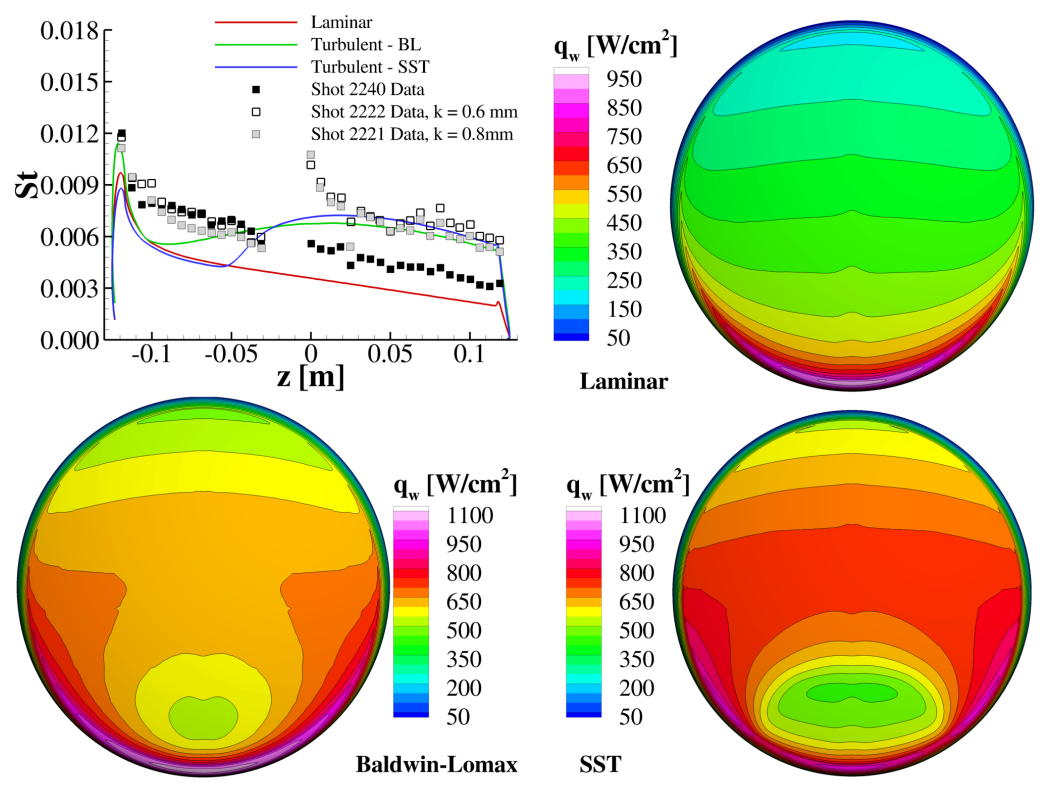

Figure 6. Laminar and turbulent capsule simulations for $P_{0}=50 \mathrm{MPa}$ and $\mathrm{H}_{0}=10 \mathrm{MJ} / \mathrm{kg}$ with smooth and tripped measured data comparisons. 


\section{Analysis Results}

\section{A. Boundary Layer Trip Sizing and Effectiveness}

A pretest computational analysis was performed to determine the trip heights to be manufactured for testing. Trip heights that would effectively cause the flow to transition from laminar to turbulent were desired. A range of stagnation enthalpies and stagnation pressures, shown in Table 1, were considered.

Table 1. Stagnation Conditions Used in Trip Sizing Study

\begin{tabular}{c|cc} 
Case & $P_{0}[\mathrm{MPa}]$ & $H_{0}[\mathrm{MJ} / \mathrm{kg}]$ \\
\hline A & 20.0 & 5.0 \\
B & 20.0 & 10.0 \\
C & 20.0 & 20.0 \\
D & 40.0 & 5.0 \\
E & 40.0 & 10.0 \\
F & 40.0 & 20.0 \\
G & 60.0 & 5.0 \\
H & 60.0 & 10.0 \\
I & 60.0 & 20.0
\end{tabular}

Figure 7 shows the computed boundary layer thickness, $\delta$, and momentum thickness Reynolds number, $R e_{\theta}$, on the capsule heatshield for the conditions selected. Also noted is the planned location of the trip elements on the test article. Case $\mathrm{F}$ was chosen as the baseline condition to size the trips for all other conditions. Table 2 shows the $k / \delta$ values chosen for the assessment as well as the resulting trip heights required to obtain the desired $k / \delta$ for the boundary layer thickness predicted for Case $\mathrm{F}$ at the desired trip location. Here $k$ is the height of the trip and $k / \delta$ is a non-dimensional scaling parameter used to measure the trip effectiveness for different flow conditions.

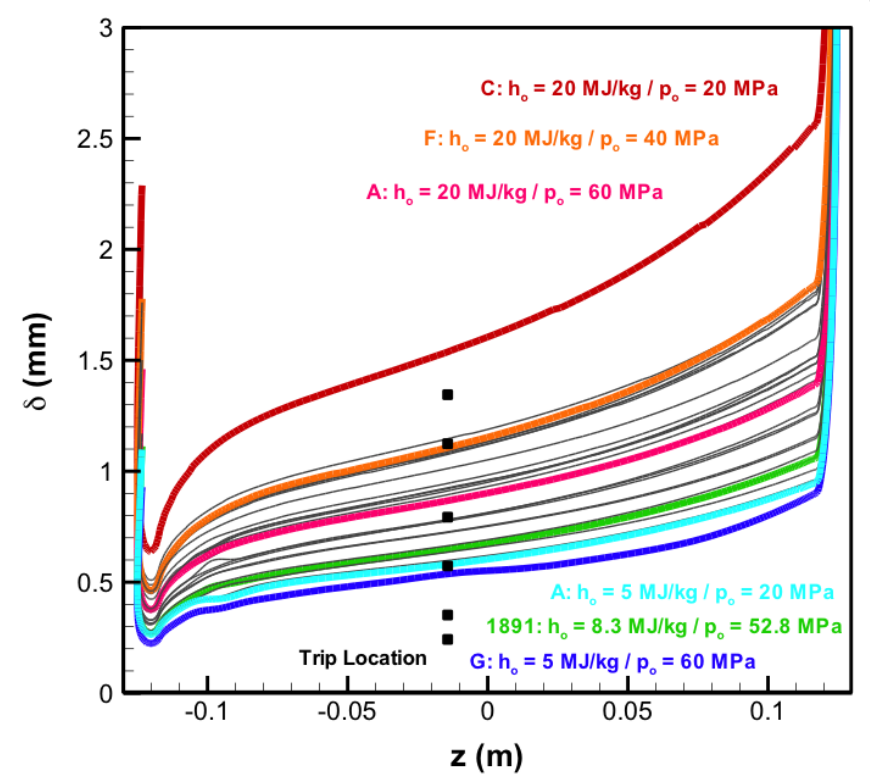

(a) Boundary Layer Thickness

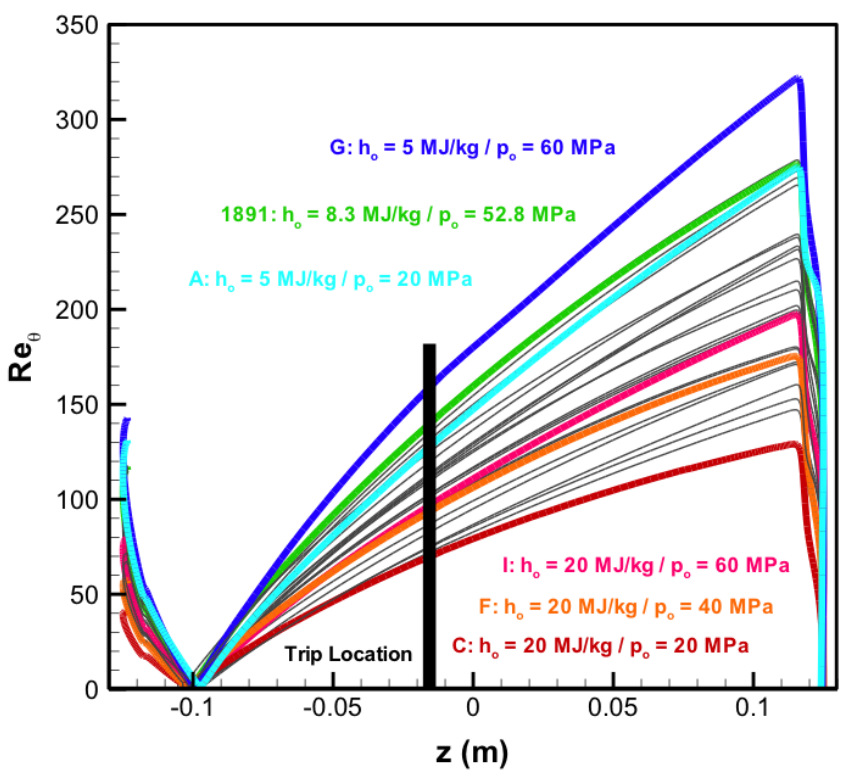

(b) Boundary Layer Momentum Thickness Reynolds Number, $R e_{\theta}$

Figure 7. Boundary layer parameters used in trip sizing study

Table 2. Case F Boundary Layer Scaling Parameters, $\delta=1.103 \mathrm{~mm}$

\begin{tabular}{l|cccccc}
$k / \delta$ & 0.2 & 0.3 & 0.5 & 0.7 & 1.0 & 1.2 \\
$\mathrm{k}[\mathrm{mm}]$ & 0.22 & 0.33 & 0.55 & 0.77 & 1.10 & 1.32
\end{tabular}

From previous experience ***FIND REFERENCES***, the boundary layer is expected to trip at values of $k / \delta$ between 0.3 and 1.0, depending on the value of $R e_{\theta}$. The six trip heights chosen for this testing provided a wide range of $k / \delta$ options 
across the desired test conditions. For Case $\mathrm{C}$ with the thickest boundary layer, the largest trip would provide a $k / \delta$ value of 0.86 , and for Case $\mathrm{G}$ with the thinnest boundary layer, the smallest trip would provide a $k / \delta$ value of 0.41 , both of which are within the range expected to trip the boundary layer.

Post-test analysis showed a wide range of $k / \delta$ values were achieved during testing. Boundary layer thickness values were computed based on the as-measured reservoir stagnation conditions from the testing according to the procedures discussed in Section II. For the low enthalpy $3 \mathrm{MJ} / \mathrm{kg}$ condition, a $0.6 \mathrm{~mm}$ trip was used and a $k / \delta$ of 0.93 was achieved. As a result of the high $k / \delta$, fully turbulent flow was attained downstream of the trip. However, at a high enthalpy and high pressure condition, (40 MPa and $20 \mathrm{MJ} / \mathrm{kg}$ ), the taller $0.8 \mathrm{~mm}$ trip was not as effective. The $k / \delta$ value computed for these test conditions was 0.75 , but the low freestream Reynolds number of $1.8 \times 10^{5}$, based on the heatshield diameter, prevented the flow from transitioning to fully turbulent with the large trip.

A high pressure, low enthalpy condition was tested with two different trip heights of $0.6 \mathrm{~mm}$ and $0.8 \mathrm{~mm}$. At these conditions, the boundary layer was thin enough $(0.7 \mathrm{~mm})$ that both trip heights effectively tripped the boundary layer to fully turbulent. These trips resulted in $k / \delta$ values of 0.84 and 1.13 , respectively.

**ANY TRENDS IN EFFECTIVENESS VS. RE_THETA??***

\section{B. Validation of Capsule Surface Heat Flux Predictions}

For each of the conditions tested in the HIEST facility during the Apollo capsule test campaign, the computational results along the heatshield centerline were compared with the heat flux data measured in the tunnel. Data was obtained for both smooth wall conditions and tripped conditions, some with multiple trip heights for a given freestream condition. Table 3 shows the nozzle stagnation conditions examined for the Apollo capsule during this test series, as well as the computed freestream conditions for the capsule analysis.

Table 3. Nozzle Stagnation and Capsule Freestream Conditions Analyzed for Capsule Test Series

\begin{tabular}{c|cc|ccccc} 
Shot & $P_{0}[\mathrm{MPa}]$ & $H_{0}[\mathrm{MJ} / \mathrm{kg}]$ & $\rho_{\infty}\left[\mathrm{kg} / \mathrm{m}^{3}\right]$ & $V_{\infty}[\mathrm{m} / \mathrm{s}]$ & $T_{\infty}[\mathrm{K}]$ & $T_{v, \infty}[\mathrm{K}]$ & $\operatorname{Re}_{D} \times 10^{-5}$ \\
\hline 2216 & 31.86 & 6.22 & 0.0204 & 3299.33 & 569.62 & 606.70 & 5.497 \\
2218 & 31.08 & 3.64 & 0.0264 & 2716.69 & 315.18 & 479.03 & 8.875 \\
2220 & 41.54 & 20.76 & 0.0103 & 5631.80 & 2190.24 & 2194.60 & 1.823 \\
2221 & 60.02 & 9.39 & 0.0278 & 3986.06 & 1024.39 & 1029.62 & 6.029 \\
2232 & 12.72 & 4.63 & 0.0102 & 2864.18 & 368.36 & 588.61 & 3.251 \\
2233 & 15.44 & 2.98 & 0.0168 & 2330.92 & 206.61 & 519.36 & 6.733
\end{tabular}

One test condition at a low stagnation enthalpy and high stagnation pressure showed natural boundary layer transition along the heatshield centerline. Figure 9 shows the comparison of the data from shot 2218 without trips, shot 2242 at similar conditions with an array of trips $0.6 \mathrm{~mm}$ tall, as well as the computational simulations for a non-catalytic wall boundary at laminar and turbulent conditions. The heat flux in the laminar region prior to transition is under-predicted by the laminar flow prediction, and as was shown previously, catalycity has a minimal effect on the wall heat flux at these conditions, so differences are likely due to other inaccuracies in the modeling.

The turbulent predictions were again performed with the Baldwin-Lomax and SST turbulence models. The transitional data from shot 2218 between $\mathrm{z}=-0.05 \mathrm{~m}$ and $\mathrm{z}=-0.02 \mathrm{~m}$ is well predicted by the SST turbulence model, but the fully turbulent data from both test runs for $\mathrm{z}$ greater than $0.0 \mathrm{~m}$ is better predicted by the Baldwin-Lomax turbulence model, but still overpredicted by both models in this region. Due to the complex nature of predicting boundary layer transition, it is likely serendipitous that the transition location and transitional data are so well predicted by the SST turbulence model. The momentum thickness Reynolds number, $R e_{\theta}$, was extracted from the CFD prediction at the sensor last observed to be laminar ( $\left.\mathrm{z}=-0.05 \mathrm{~m}\right)$. The $R e_{\theta}$ value was computed to be 76.7, which is lower than the transition $R e_{\theta}$ values observed in other capsule testing from a range of test facilities ${ }^{6}$. Data from higher enthalpy facilities similar to HIEST were also included in the study, although with a $\mathrm{CO}_{2}$ test gas, but the transition $R e_{\theta}$ predicted for data obtained in these facilities agreed well with that of the data obtained in facilities with an air test gas. 


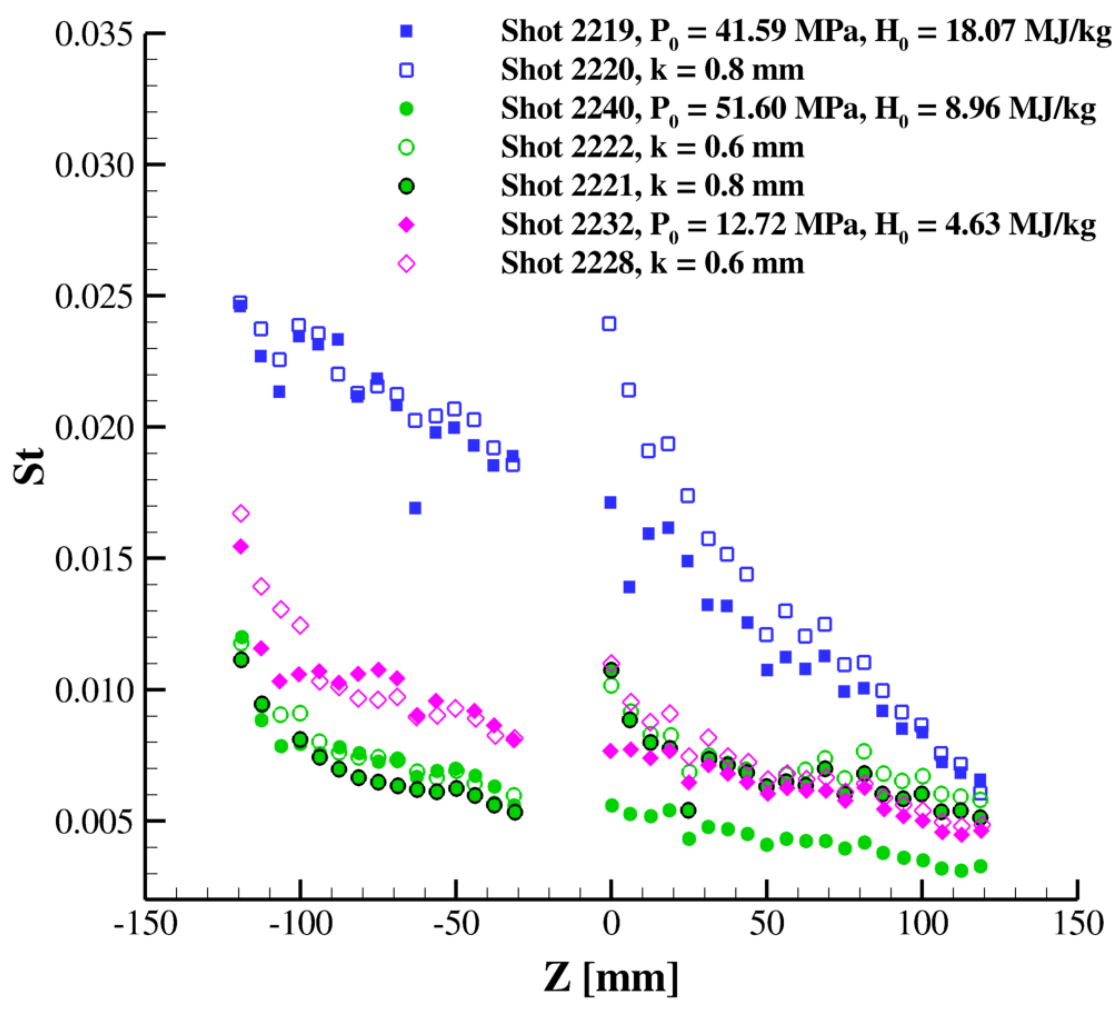

Figure 8. Heatshield Centerline Data

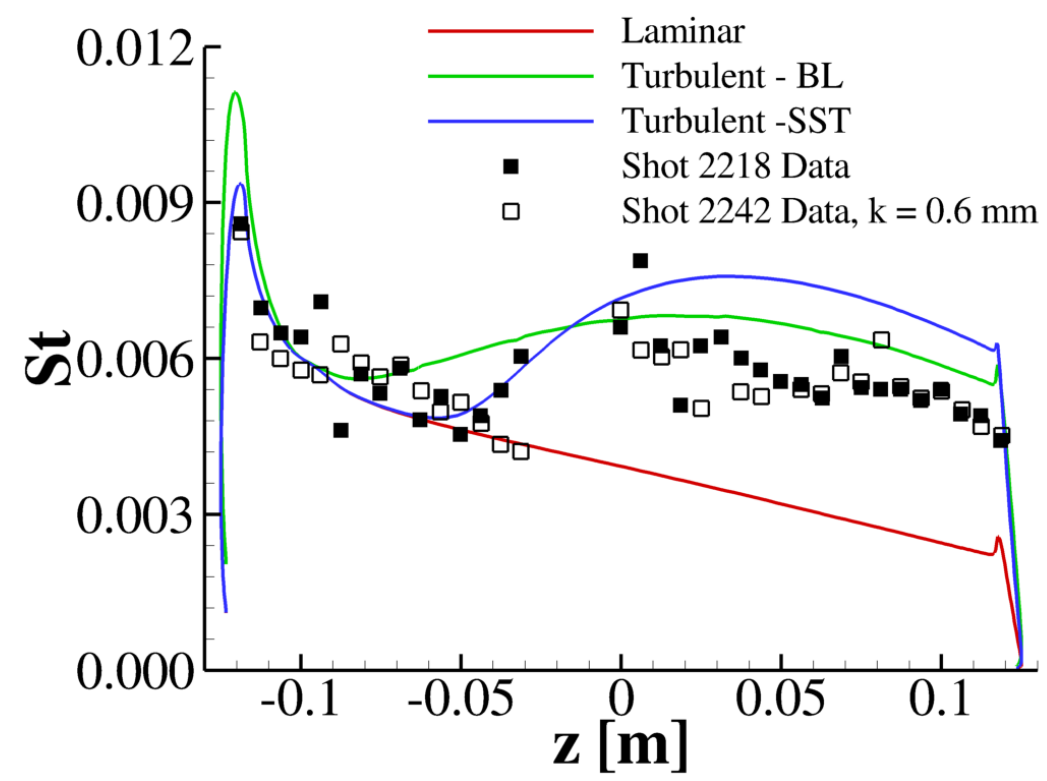

Figure 9. Shot 2218 Natural Transition, $H_{0}=3.64 \mathrm{MJ} / \mathrm{kg}, P_{0}=31.08 \mathrm{MPa}$ 


\section{Computational Predictions of Nozzle Wall Pressure}

For the runs in Table 4, pressures measured at axial stations along the nozzle wall were provided. The locations of the pressure sensors can be seen in Figure 10. The computational predictions were extracted along the nozzle wall at the sensor locations and compared to the pressure traces measured in the tunnel.

Table 4. Stagnation Conditions Analyzed for Nozzle Pressure Sensors

\begin{tabular}{c|cc} 
Shot & $P_{0}[\mathrm{MPa}]$ & $H_{0}[\mathrm{MJ} / \mathrm{kg}]$ \\
\hline 2341 & 44.62 & 20.49 \\
2346 & 45.05 & 22.23 \\
2347 & 56.59 & 8.05
\end{tabular}

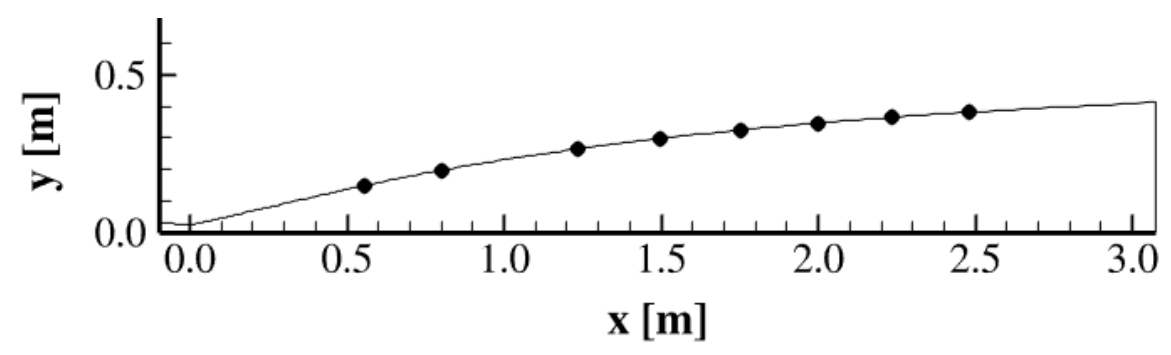

Figure 10. Nozzle Pressure Sensor Locations

The computational predictions for these conditions were run with a steady-state assumption, so there was no physical time component to the simulations. For this reason, a time when the shock passed by the pressure sensors had to be assumed for the computational predictions in order for the test data and computational predictions to be compared. This time was selected by examination of the time traces in the experimental data and selecting the time that the shock passed to correspond to the first spike in pressure seen in the first pressure sensor. This time was imposed on all sensors down the nozzle without taking into account the shock speed. While the shock wave moves quickly down the nozzle, the time that the shock passes each sensor will vary. It is recognized, therefore, that the assumption of a constant time of shock passage for each sensor is not accurate, but is sufficient for this analysis.

Figure 11 shows the comparison of the pressures measured at each of the nozzle sensor locations, shown in the black lines, with the computationally predicted pressures at the discrete points. The high pressures measured near the throat of the nozzle are predicted well with the computations, but farther down the nozzle, the predicted pressures are less accurate and generally over predict the measurements. ${ }^{* *}$ CALCULATE PERCENTAGE DIFFERENCE IN PRESSURES** Different assumptions for catalycity and chemistry models were made in an attempt to understand these differences. However, these modeling assumptions had little effect on the predicted pressures. 


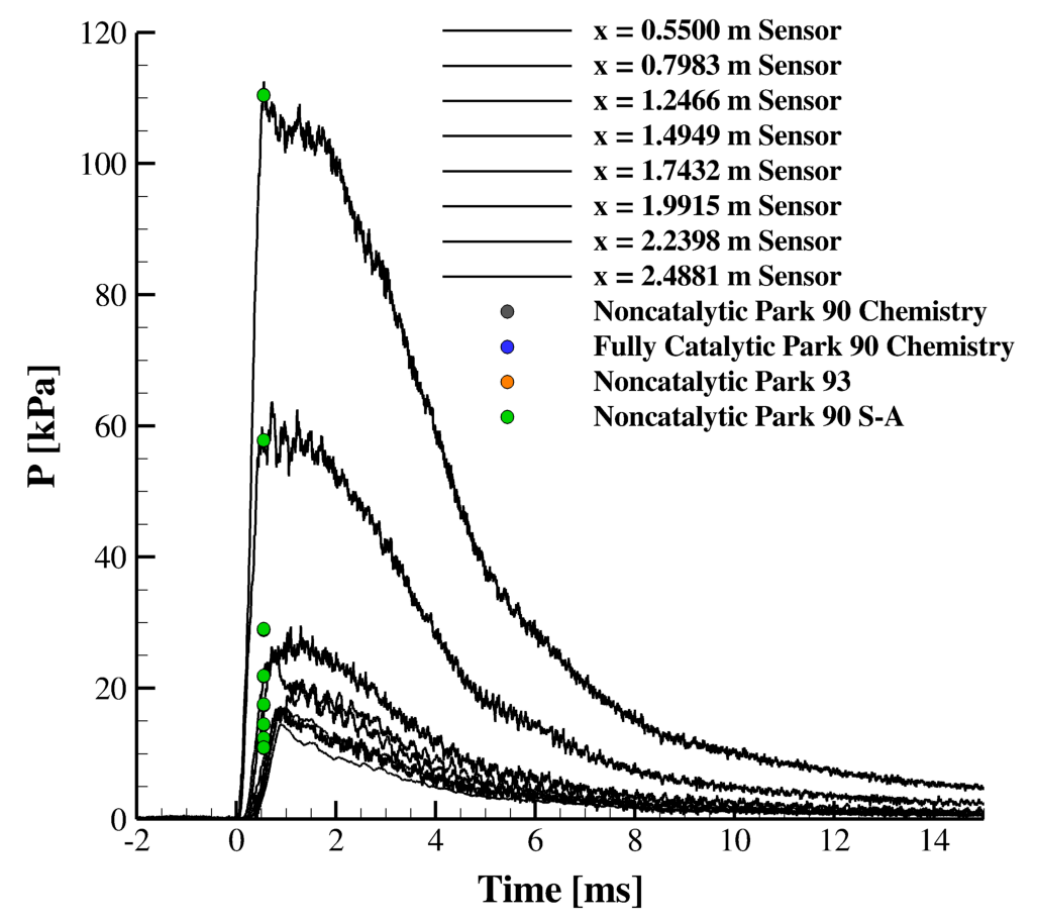

Figure 11. Shot 2341 Nozzle Wall Pressure Comparison 


\section{Conclusions}

A computational analysis has been used to support the assessment of data obtained at the HIEST high enthalpy facility at JAXA-KSC. A pretest analysis sized boundary layer trips that were expected to effectively trip the boundary layer from laminar to turbulent. Boundary layer trips ranging in height from $0.2 \mathrm{~mm}$ to $1.3 \mathrm{~mm}$ were recommended. Trip arrays of $0.6 \mathrm{~mm}$ and 0.8 $\mathrm{mm}$ height were tested over a range of stagnation enthalpy and stagnation pressure conditions.

The post-test analysis included an evaluation of the smooth body heat transfer prediction capabilities using the DPLR code at high enthalpy conditions and an assessment of the trip effectiveness for the manufactured trip heights over a range of boundary layer conditions. The $0.6 \mathrm{~mm}$ and $0.8 \mathrm{~mm}$ trip heights provided a sufficient range of $k / \delta$ to effectively trip the boundary layer from laminar to turbulent. For conditions with high stagnation pressure, the trips were less effective at tripping the boundary layer due to the lower values of $R e_{\theta}$.

Continued work would include additional comparisons of the nozzle pressures, and analysis to understand the discrepancies in the predictions downstream in the nozzle away from the throat.

\section{Acknowledgments}

This work was sponsored in part by a Space Act Agreement collaboration between NASA and the Japan Aerospace Exploration Agency.

\section{References}

${ }^{1}$ Itoh, K., Ueda, S., Komuro, T., Sato, K., Tanno, H., Takahashi, M., "Hypervelocity Research Using a High Enthalpy Shock Tunnel HIEST," 9th International Space Planes and Hypersonic Systems and Technologies Conference, AIAA Paper 99-4960, November 1999.

${ }^{2}$ Marineau, E., Laurence, S., Hornung, H., "Apollo-Shaped Capsule Boundary Layer Transition at High-Enthalpy in T5," 48th AIAA Aerospace Sciences Meeting Including the New Horizons Forum and Aerospace Exposition, AIAA 2010-446, January 2010.

${ }^{3}$ Tanno, H., Komuro, T., Sato, K., Itoh, K., "Aeroheating measurement of Apollo-shaped capsule with boundary layer trip in the free-piston shock tunnel HIEST," 52nd Aerospace Sciences Meeting, AIAA 2014-0434, January 2014.

${ }^{4}$ Wright, M., Candler, G., "Data-Parallel Line Relaxation Method for the Navier-Stokes Equations," AIAA Journal, Vol. 36, Number 9, September 1998.

${ }^{5} \mathrm{McBride}$, B., Gordon, S., "Computer Program for Calculation of Complex Chemical Equilibrium Compositions and Applications, II. Users Manual and Program Description," NASA Reference Publication, RP-1311-P2, June 1996.

${ }^{6}$ Hollis, B., Berger, K., Horvath, T., Coblish, J., Norris, J., Lillard, R., Kirk, B., "Aeroheating Testing and Predictions for Project Orion CEV at Turbulent Conditions," 46th AIAA Aerospace Sciences Meeting, AIAA 2008-1226, January 2008. 